\title{
ORIGINAL
}

\section{Antimicrobial de-escalation in the critically ill patient and assessment of clinical cure: the DIANA study}

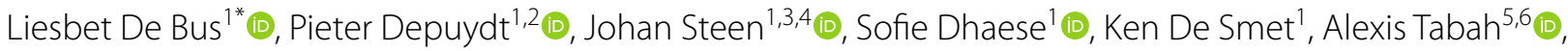
Murat Akova ${ }^{7}$, Menino Osbert Cotta ${ }^{8,9}$, Gennaro De Pascale ${ }^{10,11} \mathbb{D}$, George Dimopoulos ${ }^{12,13} \mathbb{D}$,

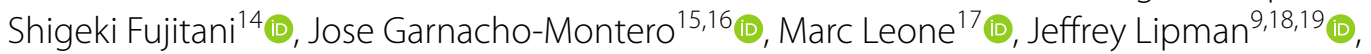
Marlies Ostermann ${ }^{20}$ (D) José-Artur Paiva ${ }^{21,22}$, Jeroen Schouten ${ }^{23,24} \mathbb{B}$, Fredrik Sjövall ${ }^{25,26}$ (D),

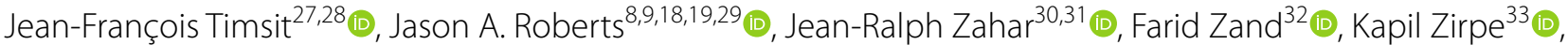
Jan J. De Waele ${ }^{1}$ il and DIANA study group

(c) 2020 The Author(s)

\begin{abstract}
Purpose: The DIANA study aimed to evaluate how often antimicrobial de-escalation (ADE) of empirical treatment is performed in the intensive care unit (ICU) and to estimate the effect of ADE on clinical cure on day 7 following treatment initiation.
\end{abstract}

Methods: Adult ICU patients receiving empirical antimicrobial therapy for bacterial infection were studied in a prospective observational study from October 2016 until May 2018. ADE was defined as (1) discontinuation of an antimicrobial in case of empirical combination therapy or (2) replacement of an antimicrobial with the intention to narrow the antimicrobial spectrum, within the first 3 days of therapy. Inverse probability (IP) weighting was used to account for time-varying confounding when estimating the effect of ADE on clinical cure.

Results: Overall, 1495 patients from 152 ICUs in 28 countries were studied. Combination therapy was prescribed in $50 \%$, and carbapenems were prescribed in $26 \%$ of patients. Empirical therapy underwent ADE, no change and change other than ADE within the first 3 days in 16\%, 63\% and 22\%, respectively. Unadjusted mortality at day 28 was $15.8 \%$ in the ADE cohort and $19.4 \%$ in patients with no change $[p=0.27$; RR 0.83 (95\% Cl 0.60-1.14)]. The IP-weighted relative risk estimate for clinical cure comparing ADE with no-ADE patients (no change or change other than ADE) was 1.37 (95\% Cl 1.14-1.64).

Conclusion: ADE was infrequently applied in critically ill-infected patients. The observational effect estimate on clinical cure suggested no deleterious impact of ADE compared to no-ADE. However, residual confounding is likely.

Keywords: Antimicrobial de-escalation, Intensive care unit, Bacterial infection, Empirical therapy, Clinical cure

*Correspondence: liesbet.debus@ugent.be

${ }^{1}$ Department of Critical Care Medicine, Ghent University Hospital, C. Heymanslaan 10,9000 Ghent, Belgium

Full author information is available at the end of the article

\section{Introduction}

Antimicrobial de-escalation (ADE) is a treatment strategy pursuing early adequate antimicrobial therapy as well as a reduction in the overall use of broad-spectrum agents, with the aim to contain subsequent emergence of multidrug resistance [1-4]. De-escalation may be 
achieved through replacement of a broad-spectrum antimicrobial by an antimicrobial agent with a narrower spectrum or a lower ecological impact or by discontinuation of one or more antimicrobials of empirical combination therapy [4-7]. Internationally, ADE is recognized as a key component of antimicrobial stewardship [8-10].

Information on how often $\mathrm{ADE}$ is performed in everyday practice on a world-wide scale is lacking. Whereas the extended prevalence of infection in intensive care studies provided more insight in the global epidemiology of infections and antimicrobial use in critically ill patients; international studies mapping complete antimicrobial treatment courses in intensive care unit (ICU) patients are unavailable at present $[11,12]$.

Many observational studies and few randomized controlled trials (RCT) evaluated ADE and the impact thereof on patient outcome. RCTs have been unable to show convincing evidence that ADE is definitely safe, while systematic reviews have indicated a positive influence of $\mathrm{ADE}$ on mortality [4, 13-15]. Controversies regarding the safety of ADE nonetheless still exist as various definitions were used and antimicrobials were predominantly de-escalated in patients with microbiologically confirmed infections and a favorable clinical course. As such, observational studies are prone to bias [16].

The aims of the DetermInants of Antimicrobial use aNd de-escalAtion in critical care (DIANA) study were to determine how often $\mathrm{ADE}$ of an empirically prescribed therapy is performed in an ICU population and to estimate the effect of ADE on clinical cure on day 7 following initiation of empirical therapy, while adequately accounting for drivers of ADE that may evolve over time and also affect clinical outcome.

\section{Methods}

The DIANA study was a multicenter international observational cohort study investigating adult critically ill patients receiving empirical antimicrobial therapy for suspected or confirmed bacterial infections in the ICU. An international steering committee was established in 2015 and consisted of members of the European Society of Intensive Care Medicine (ESICM) Infection section. A network of national coordinators recruited investigators, coordinated study participation and monitored local ethics committee approval at each participating center. The Ghent University Hospital Ethics Committee approved the study (registration number B670201629297). The study was not funded and participation was voluntary. The trial was registered in ClinicalTrials.gov (NCT02920463).

\section{Take-home message}

ADE was performed within 3 days following empirical prescription in only $16 \%$ of critically ill-infected patients, despite the fact that half of the empirical prescriptions consisted of combination therapy and one-quarter contained a carbapenem. The observational effect estimate on clinical cure suggested no deleterious impact of ADE compared to no-ADE; however, residual confounding is likely to be present.

\section{Participants}

Patients were eligible for inclusion if they were 18 years or older and admitted to an ICU with an anticipated need of at least $48 \mathrm{~h}$ of ICU support. An empirical antimicrobial therapy had to be initiated in the ICU or no more than $24 \mathrm{~h}$ prior to ICU admission to treat a community-, healthcare-, hospital- or ICU-acquired bacterial infection. Antimicrobial therapy was defined as empirical in case the causative pathogen and susceptibility pattern were unidentified at the time of initiation of the antimicrobials. Patients could be included once. Informed consent was either obtained or waived according to local ethics committee requirements. Participating ICUs were asked to include all consecutive patients who were eligible during a convenient 2-week period, or an extended time period to provide the opportunity to include 10 patients. Patients could be included from October 2016 until May 2018.

\section{Data collection}

Data were submitted through an Electronic Data Capture platform $\left(\mathrm{CASTOR}^{\mathrm{TM}}\right)$ [17]. Patient, infection and antimicrobial treatment-related data were collected from the day of study inclusion (day 0), defined as the start date of empirical antimicrobial therapy, until day 28 . No interventions or measurements other than those that were standard of care were performed.

Patient-related data included: age; sex; co-morbidities; previous antimicrobial and hospital exposure; admission category and diagnosis. Severity of illness was evaluated using Acute Physiology And Chronic Health Evaluation (APACHE) II and Simplified Acute Physiology Score (SAPS) II on the day of ICU admission; Sequential Organ Failure Assessment (SOFA) scores were collected on the day of ICU admission, day 0 and day 3 (online supplement 1). The presence (i.e., multi-drug-resistant (MDR) pathogens present on ICU admission and/or detected before day 2) or emergence (i.e., MDR pathogens detected between day 2 and day 28 and not present before) of MDR pathogens was evaluated. Multi-drug resistance was defined as a pathogen producing extended-spectrum beta-lactamase (ESBL) or carbapenemase, Stenotrophomonas maltophilia, methicillin-resistant Staphylococcus aureus, vancomycin-resistant Enterococcus sp., or a 
pathogen resistant to 3 or more antimicrobial classes in accordance with the publication of Magiorakos et al. [18]. MDR-tables were constructed as guidance (online supplement 2). The need for supportive therapy, number of days in the ICU and hospital, ICU and hospital mortality were recorded until day 28 . The clinical response of the patient for the initial infection was assessed by the treating clinician on day 7. Clinical cure was defined as survival and resolution of all signs and symptoms related to the infection.

Infection-related data included: source, need for source control, causative pathogens and susceptibility patterns. Antimicrobial treatment-related data included: type and timing of all antimicrobial agents that were initiated. Indications for stopping, switching or addition of an agent were recorded. Infection relapse, defined as an infection with the same causative microorganism and source that occurred after discontinuation of all antimicrobial agents for the primary infection, was evaluated until day 28. Additional antimicrobial therapy following study inclusion and antimicrobial-free days were assessed at 28 days following inclusion.

In addition, each participating ICU had to provide information on local antimicrobial resistance, organizational aspects of the ICU and presence of antimicrobial stewardship interventions in the ICU, e.g., multidisciplinary staff meetings and local antimicrobial treatment guidelines.

\section{Data management}

Data monitoring was performed by two investigators (LDB, KDS)

Antimicrobial treatment courses were classified based on the first modification of therapy (or the absence thereof) that took place between day 0 and day 3 as: "no change" (empirical therapy was maintained without modification between day 0 and day 3); "ADE" or "other change".

For the current analysis, ADE was defined as: (1) discontinuation of one or more antimicrobials of the empirical combination therapy which were considered by the treating physician to be not (or no longer) necessary for treatment of the infection within the first 3 days of initiation of empirical therapy (e.g., stopping vancomycin on day 2 following initial treatment with piperacillin-tazobactam combined with vancomycin); (2) replacement of an antimicrobial agent by another drug with the intention of the treating physician to narrow the spectrum of activity within the first 3 days of empirical therapy (e.g., replacement of meropenem by amoxicillin-clavulanate on day 2 ). In addition, physicians were asked to justify these decisions and specify the reason for treatment modification.
"Other change" was defined as: (1) the addition or replacement of an antimicrobial agent by the treating clinician within the first 3 days of empirical therapy, based on clinical deterioration or lack of clinical improvement, the presence of resistant causative and/or colonizing pathogens and/or presumed inadequacy of the initial treatment (e.g., not concordant with guidelines); (2) replacement of an antimicrobial agent within the first 3 days of empirical therapy due to side-effects of antimicrobials.

\section{Statistical analysis}

Frequencies (percentages) are reported as descriptive summary statistics for categorical variables and medians and interquartile range (IQR) (25th to 75th percentile) for continuous variables. Distributional differences for categorical patient outcomes were evaluated using a Pearson Chi-squared test or Fisher's exact test when appropriate. The Mann-Whitney $U$ test was used for comparison of non-normally distributed continuous outcomes. Risk ratios were reported for binary variables, along with 95\% confidence intervals (CIs). Unadjusted outcome analyses were performed comparing ADE and "no change" patients, and "other change" and "no change" patients.

Two primary outcome measures were defined: The incidence of ADE and clinical cure on day 7. Statistical analysis was tailored so as to emulate a hypothetical randomized trial to estimate the effect of ADE on clinical cure on day 7 (see online supplement 3 for additional statistical information) [19-23]. Inverse probability (IP) weighting was used to control for time-varying confounding that might affect both the decision of ADE on each day within the considered 4-day time period and clinical cure on day 7. Selection of these confounders was based on subject matter knowledge by means of a Delphi approach within the steering committee [24, 25]. Immunosuppression status, delta SOFA (defined as SOFA day 0 minus SOFA day 3), need and effectiveness of source control and identification of causative microbiology were selected by the panel and included in the analysis. Susceptibility pattern of the causative pathogen was selected but not included in the analysis due to incomplete timing-related data. Two additional covariates were included: (1) the continent where the ICU was located to account for missing data in certain regions; (2) the number of empirical agents to enable multiple subgroup and sensitivity analyses. Sensitivity analyses entailed inclusion of SOFA day 0, inappropriate empirical therapy and MDR colonization as covariate. The results are presented as absolute weighted risks, relative risk and 95\% CI.

Post hoc power and sample size calculations using the IP weighted analysis were performed. 
Statistical analysis was performed using $\mathrm{R}$ Statistical Software (version 3.4.2; The R Foundation for Statistical Computing. Vienna, Austria) using the packages geepack, ipw, multcomp and splines [26-30].

The Strengthening the Reporting of Observational Studies in Epidemiology (STROBE) guidelines for reporting of observational studies and the recommendations to optimize reporting of epidemiological studies on antimicrobial resistance and informing improvement in antimicrobial stewardship (STROBE-AMS) were followed [31, 32].

\section{Results}

\section{Participating intensive care units}

A total of 152 ICUs in 28 countries participated; $48 \%$ in Europe, 38\% in Asia, 9\% in America and 5\% in Australia and New-Zealand (online supplement 4). Ninety percent of participating centers were teaching hospitals, $81 \%$ were mixed ICUs and $76 \%$ worked in a closed ICU organization. Infectious disease specialists, microbiologists and clinical pharmacists joined regular multidisciplinary staff meetings in $28 \%, 24 \%$ and $22 \%$ of centers, respectively. Local $\mathrm{ADE}$ guidelines were used in $25.4 \%$ of centers. Baseline methicillin resistance of the $S$. aureus isolates was $10 \%$ (IQR 3-26) in the participating ICUs; vancomycin resistance of the enterococcus species isolates $0 \%$ (IQR $0-3$ ). ESBL production was reported in $11 \%$ (IQR 5-21) of enterobacteriaceae isolates, whereas carbapenemase production was reported in $1 \%$ (IQR $0-5)$. Detailed center characteristics are presented in online supplement 5 .

\section{Overall patient, infection and treatment characteristics}

A total of 1495 patients were available for analysis (online supplement 6). Median age was 65 (IQR 51-75) years, $61.5 \%$ were male and $66.6 \%$ were medical admissions. Patients were colonized with MDR pathogens prior to initiation of empirical antimicrobial therapy in $11.5 \%$. Patient characteristics are detailed in Table 1. Infection and treatment characteristics are described in Table 2. Combination therapy was prescribed in 50\% of empirical courses. The most frequently prescribed agents were anti-pseudomonal penicillins in combination with a beta-lactamase inhibitor, carbapenems and third-generation cephalosporins in $29.6 \%, 26 \%$ and $19.3 \%$ of patients, respectively (Table 3 ). Infections were microbiologically confirmed in $55.8 \%$. Empirical therapy was considered inappropriate by the treating clinician based on the susceptibility pattern of the causative pathogen and triggered treatment modification in $10 \%$ of patients. Median number of days in the ICU and hospital following the onset of the infection were 8 (IQR 5-18) in ICU survivors and 26 (IQR
13-28) days in hospital survivors, respectively. The 28 -day mortality rate was $19.8 \%$.

\section{Proportion of ADE patients}

During the first 3 days, empirical antimicrobial therapy was de-escalated in $16 \%(240 / 1495)$ and not changed in 63\% (934/1495). In 22\% (321/1495) of patients, another treatment change was performed. Five percent $(75 / 1495)$ of patients died during the first 3 days of therapy. A detailed description of the treatment modifications between day 0 and day 7 is available in online supplement 7.

\section{Description of ADE}

ADE consisted mainly of discontinuation of one or more components of combination therapy [52\% (125/240)], whereas $35 \%(84 / 240)$ of ADE consisted of replacement of an antimicrobial agent by another drug. Both ADE approaches were applied in 13\% (31/240) of ADE patients. The absence of microbiological confirmation and dual coverage of causative pathogens were the most prevalent incentives for discontinuation of a component of combination therapy. ADE in the form of replacement was mainly based on identification and susceptibility pattern of the causative pathogen (Table 4). The antimicrobial classes that were discontinued most often as components of a combination therapy were glycopeptides $(n=46)$, aminoglycosides $(n=43)$ and macrolides $(n=29)$. The most frequently performed switches in the setting of ADE were: piperacillin-tazobactam to a thirdgeneration cephalosporin and piperacillin-tazobactam to penicillin in combination with a beta-lactamase inhibitor. De-escalated beta-lactam prescriptions complied with the ranking developed by Weiss et al. in 91\% (69/76) of the patients [33]. Online supplement 8 contains detailed information on $\mathrm{ADE}$ practices. ADE took place on day 0 , day 1, day 2 and day 3 in 21\%,30\%,25\% and $25 \%$ of ADE patients, respectively.

\section{Patient, infection and treatment characteristics associated with ADE}

The distribution of sex, age, pre-existing co-morbidities and immunosuppression status of patients was comparable in the ADE and "no change" cohort. Prior healthcare exposure occurred in $53.3 \%$ of ADE patients and in $44.0 \%$ of "no change" patients. Differences in antimicrobial treatment exposure between hospital admission and empirical treatment initiation and pre-existing MDR colonization between the ADE and "no change" cohorts were small $(52.5 \%$ vs. $49.9 \%$, and $8.8 \%$ vs. $10.5 \%$, respectively) (Table 1).

Severity of illness at ICU admission, SOFA day 0 and SOFA day 3 had comparable distributions in the ADE and 


\section{Table 1 Patient characteristics}

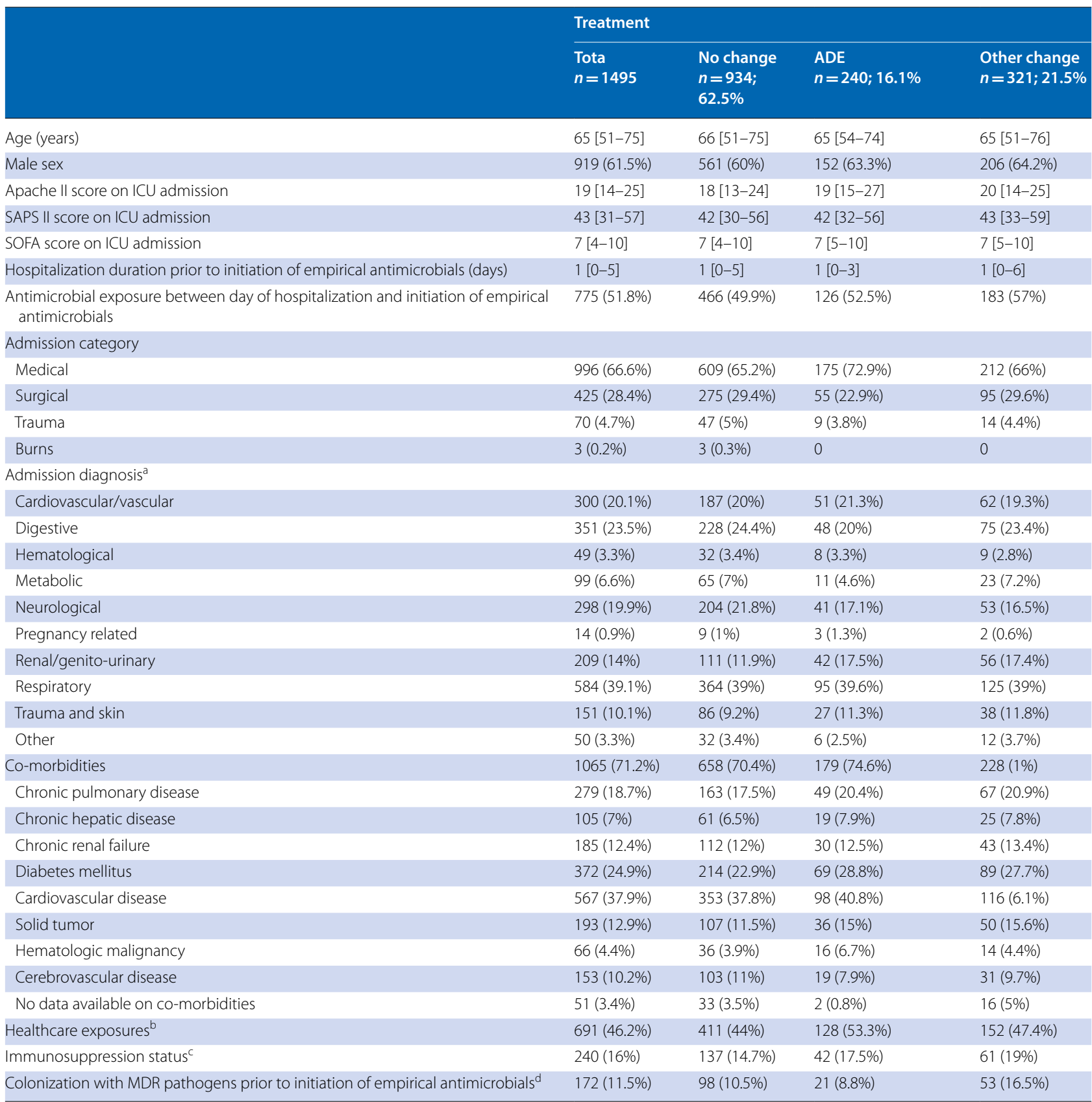

Results are shown as $n$ (\%) or median [IQR] where applicable

$A D E$ antimicrobial de-escalation, $A P A C H E$ acute physiology and chronic health evaluation, ICU intensive care unit, MDR multidrug-resistant, SAPS simplified acute physiology score, SOFA sequential organ failure assessment

a Multiple admission diagnoses may be assigned to one patient

b Hospitalization for $\geq 2$ days in the 12 months prior to study inclusion, antimicrobial exposure in the last 3 months prior to study inclusion, resident in a nursing home or long-term care facility, receiving chronic hemodialysis or receiving invasive procedures (at home or in an outpatient clinic) in the last 30 days prior to study inclusion

c Congenital immunodeficiency, neutropenia (absolute neutrophil count $<1000$ neutrophils $/ \mu \mathrm{l}$ ), patient receiving corticosteroid treatment (prednisolone or equivalent $>0.5 \mathrm{mg} / \mathrm{kg} / \mathrm{day}$ for $>3$ months prior to study inclusion), solid organ transplant patient receiving immunosuppressive treatment, bone marrow transplant patient receiving immunosuppressive treatment, administration of chemotherapy within 1 year prior to study inclusion, administration of radiotherapy within 1 year prior to study inclusion, patient with autoimmune disease receiving immunosuppressive treatment, HIV or AIDS

${ }^{d}$ Defined as all MDR pathogens presumed to be already present on ICU admission, within 1 year prior to study inclusion combined with all MDR pathogens not present on ICU admission and detected before day 2 (day 0 is considered start date of the empirical antimicrobial therapy) 
Table 2 Infection and treatment characteristics

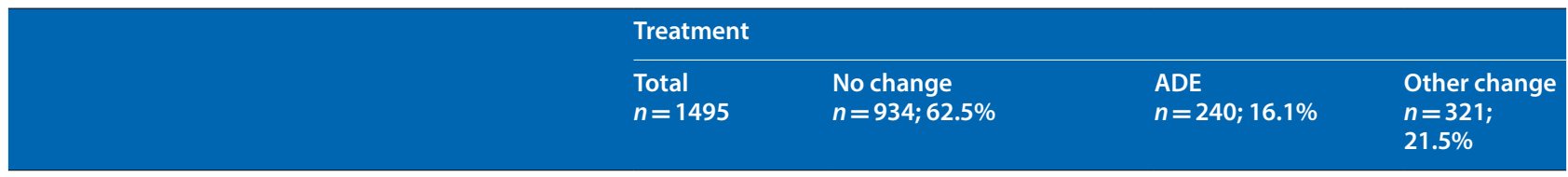

\section{Infection characteristics}

\begin{tabular}{|c|c|c|c|c|}
\hline \multicolumn{5}{|l|}{ Source of infection ${ }^{a}$} \\
\hline Abdominal & $272(18.2 \%)$ & $170(18.2 \%)$ & 37 (15.4\%) & 65 (20.2\%) \\
\hline Cardiovascular and intravascular & $50(3.3 \%)$ & $27(2.9 \%)$ & $11(4.6 \%)$ & $12(3.7 \%)$ \\
\hline Catheter-related & $46(3.1 \%)$ & $25(2.7 \%)$ & $5(2.1 \%)$ & $16(5 \%)$ \\
\hline Respiratory & $717(48 \%)$ & $464(49.7 \%)$ & $106(44.2 \%)$ & $147(45.8 \%)$ \\
\hline Skin & $107(7.2 \%)$ & $54(5.8 \%)$ & $23(9.6 \%)$ & $30(9.3 \%)$ \\
\hline Uro-genital & $149(10 \%)$ & $76(8.1 \%)$ & $34(14.2 \%)$ & $39(12.1 \%)$ \\
\hline Other & $117(7.8 \%)$ & $71(7.6 \%)$ & $22(9.2 \%)$ & $24(7.5 \%)$ \\
\hline Unknown & $171(11.4 \%)$ & $119(12.7 \%)$ & $22(9.2 \%)$ & $30(9.3 \%)$ \\
\hline Diagnostic certainty (range 1-10) & $10[8-10]$ & $10[8-10]$ & $10[9-10]$ & $10[8-10]$ \\
\hline Septic shock & $334(22.3 \%)$ & $201(21.5 \%)$ & $71(29.6 \%)$ & $62(19.3 \%)$ \\
\hline SOFA day 0 & $7[4-10]$ & $7[4-10]$ & $7[510]$ & $7[5-9.5]$ \\
\hline SOFA day $3^{b}$ & $5[3-8]$ & $5[38]$ & $4[2-8]$ & $6[4-9]$ \\
\hline Microbiologically documented infection & $834(55.8 \%)$ & $448(48 \%)$ & $178(74.2 \%)$ & $208(64.8 \%)$ \\
\hline Polymicrobial infection & $275(18.4 \%)$ & $162(17.3 \%)$ & $39(16.3 \%)$ & $74(23.1 \%)$ \\
\hline Bacteremia & $293(19.6 \%)$ & $132(14.1 \%)$ & $78(32.5 \%)$ & $83(25.9 \%)$ \\
\hline Need for source control & $349(23.3 \%)$ & $192(20.6 \%)$ & $65(27.1 \%)$ & $92(28.7 \%)$ \\
\hline Effectiveness of source control on day 3 ( $n=$ number of & $214 / 349(61.3 \%)$ & $116 / 192(60.4 \%)$ & $49 / 65(75.4 \%)$ & $49 / 92(53.2 \%)$ \\
\hline
\end{tabular}

patients who need source control)

\section{Treatment characteristics}

Empirical antimicrobial prescription

\begin{tabular}{|c|c|c|c|c|}
\hline Monotherapy & 753 (50.4\%) & 538 (57.6\%) & 43 (17.9\%) & $172(53.6 \%)$ \\
\hline Combination therapy & $742(49.6 \%)$ & $396(42.4 \%)$ & $197(82.1 \%)$ & $149(46.4 \%)$ \\
\hline 2 Antimicrobial agents & 519 & 285 & 119 & 115 \\
\hline 3 Antimicrobial agents & 181 & 95 & 59 & 27 \\
\hline 4 Antimicrobial agents & 38 & 15 & 18 & 5 \\
\hline 5 Antimicrobial agents & 4 & 1 & 1 & 2 \\
\hline Duration of treatment for the infection under study (days) & $10[7-16]$ & $9[6-15]$ & $10[7-15]$ & $12[7-17]$ \\
\hline Inappropriate empirical antimicrobial prescription ${ }^{b}$ & $151(10 \%)$ & $67(7.2 \%)$ & $10(4.2 \%)$ & $74(23.1 \%)$ \\
\hline
\end{tabular}

Results are shown as $n$ (\%) or median [IQR] where applicable

$A D E$ antimicrobial de-escalation, SOFA sequential organ failure assessment

a Multiple infection diagnoses may be assigned to one patient; infection focusses with an overall frequency of less than $3 \%$ were included in the 'other infection diagnosis' category and include: bone and joint infections; central nervous system infections; neutropenic fever; other unspecified infections

b Presence of a causative pathogen resistant to the initial agent(s) leading to addition or replacement of the empirical antimicrobial prescription

"no change" cohort. Septic shock at presentation was more prevalent in ADE compared to "no change" patients (29.6\% vs. $21.5 \%$, respectively). ADE patients had higher rates of microbiological confirmation ( $74.2 \%$ vs. $48 \%$, respectively), bacteremia ( $32.5 \%$ vs. $14.1 \%$, respectively) and need for source control ( $27.1 \%$ vs. $20.6 \%$, respectively) compared to "no change" patients. Online supplements 9 and 10 contain details related to causative microbiology and resistance patterns. The use of empirical antimicrobial combination therapy differed between both strategies [82.1\% (ADE) vs. $42.4 \%$ ("no change")], but the overall treatment durations were comparable (10 days (IQR 7-15) in ADE cohort vs. 9 days (IQR 6-15) in "no change" cohort) (Table 2).

\section{Outcome}

Delta SOFA and rate of clinical cure on day 7 were higher in ADE compared to "no change" patients [2 (IQR 0-4) vs. 1 (IQR $0-3$ ); $p<0.001$ and $57.9 \%$ vs. $42.7 \%$; RR 1.34 (1.18-1.52); $p<0.001$, respectively]. Emergence of MDR was $7.5 \%$ in $\mathrm{ADE}$ patients compared to $11.9 \%$ in "no change" patients (RR $0.63(0.39-1.01) ; p=0.06$,). Infection relapse rate and antimicrobial-free days at day 28 
Table 3 Empirical antimicrobial therapy

\begin{tabular}{|c|c|c|c|c|}
\hline \multirow[t]{2}{*}{ Overall use } & \multicolumn{4}{|l|}{ Treatment } \\
\hline & Total $n=1495$ & No change $n=934$ & ADE $n=240$ & Other change $n=321$ \\
\hline $\begin{array}{l}\text { Antipseudomonal penicillins }+\beta \text {-lactamase } \\
\text { inhibitor }\end{array}$ & $442(29.6 \%)$ & $265(28.4 \%)$ & 91 (37.9\%) & $86(26.8 \%)$ \\
\hline Carbapenems & $389(26 \%)$ & $248(26.6 \%)$ & $65(27.1 \%)$ & $76(23.7 \%)$ \\
\hline Third-generation cephalosporins & $289(19.3 \%)$ & $170(18.2 \%)$ & $57(23.8 \%)$ & $62(19.3 \%)$ \\
\hline Glycopeptides & $258(17.3 \%)$ & $145(15.5 \%)$ & $72(30 \%)$ & $41(12.8 \%)$ \\
\hline Penicillins + $\beta$-lactamase inhibitor & $202(13.5 \%)$ & $138(14.8 \%)$ & $24(10 \%)$ & $40(12.5 \%)$ \\
\hline Fluoroquinolones & $153(10.2 \%)$ & $89(9.5 \%)$ & $26(10.8 \%)$ & $38(11.8 \%)$ \\
\hline Macrolides & $119(8 \%)$ & $54(5.8 \%)$ & $41(17.1 \%)$ & $24(7.5 \%)$ \\
\hline Aminoglycosides & $110(7.4 \%)$ & $39(4.2 \%)$ & $52(21.7 \%)$ & $19(5.9 \%)$ \\
\hline Nitroimidazoles & $86(5.8 \%)$ & $41(4.4 \%)$ & $21(8.8 \%)$ & $24(7.5 \%)$ \\
\hline Clindamycin & $75(5 \%)$ & $49(5.2 \%)$ & $12(5 \%)$ & $14(4.4 \%)$ \\
\hline Linezolid & $69(4.6 \%)$ & $40(4.3 \%)$ & $17(7.1 \%)$ & $12(3.7 \%)$ \\
\hline Penicillins & $40(2.7 \%)$ & $15(1.6 \%)$ & $15(6.3 \%)$ & $10(3.1 \%)$ \\
\hline Fourth-generation cephalosporins & $36(2.4 \%)$ & $20(2.1 \%)$ & $9(3.8 \%)$ & $7(2.2 \%)$ \\
\hline Azoles & $36(2.4 \%)$ & $22(2.4 \%)$ & $3(1.3 \%)$ & $11(3.4 \%)$ \\
\hline Echinocandins & $36(2.4 \%)$ & $25(2.7 \%)$ & $5(2.1 \%)$ & $6(1.9 \%)$ \\
\hline Second-generation cephalosporins & $28(1.9 \%)$ & $15(1.6 \%)$ & $7(2.9 \%)$ & $6(1.9 \%)$ \\
\hline First-generation cephalosporins & $24(1.6 \%)$ & $12(1.3 \%)$ & $2(0.8 \%)$ & $10(3.1 \%)$ \\
\hline Tetracyclines & $22(1.5 \%)$ & $13(1.4 \%)$ & $2(0.8 \%)$ & $7(2.2 \%)$ \\
\hline Tigecycline & $22(1.5 \%)$ & $13(1.4 \%)$ & $5(2.1 \%)$ & $4(1.2 \%)$ \\
\hline Polymyxins & $19(1.3 \%)$ & $9(1 \%)$ & $3(1.3 \%)$ & $7(2.2 \%)$ \\
\hline Folate pathway inhibitors & $18(1.2 \%)$ & $13(1.4 \%)$ & $1(0.4 \%)$ & $4(1.2 \%)$ \\
\hline Daptomycin & $10(0.7 \%)$ & $7(0.7 \%)$ & $1(0.4 \%)$ & $2(0.6 \%)$ \\
\hline Polyenes & $4(0.3 \%)$ & $3(0.3 \%)$ & $1(0.4 \%)$ & 0 \\
\hline Fosfomycin & $3(0.2 \%)$ & $2(0.2 \%)$ & 0 & $1(0.3 \%)$ \\
\hline Rifampin & $3(0.2 \%)$ & $1(0.1 \%)$ & $2(0.8 \%)$ & 0 \\
\hline Fifth-generation cephalosporins & $1(0.07 \%)$ & 0 & $1(0.4 \%)$ & 0 \\
\hline Antifungal antimetabolites & $1(0.07 \%)$ & $1(0.1 \%)$ & 0 & 0 \\
\hline Monobactams & $1(0.07 \%)$ & $1(0.1 \%)$ & 0 & 0 \\
\hline Monotherapy-top 10 & $n=753$ & $n=538$ & $n=43$ & $n=172$ \\
\hline $\begin{array}{l}\text { Antipseudomonal penicillins }+\beta \text {-lactamase } \\
\text { inhibitor }\end{array}$ & $234(31.1 \%)$ & $165(30.7 \%)$ & $18(41.9 \%)$ & $51(29.7 \%)$ \\
\hline Carbapenems & $159(21.1 \%)$ & $112(20.8 \%)$ & $12(27.9 \%)$ & $35(20.3 \%)$ \\
\hline Penicillins + $\beta$-lactamase inhibitor & $130(17.3 \%)$ & $102(19 \%)$ & $4(9.3 \%)$ & $24(14 \%)$ \\
\hline Third-generation cephalosporins & $89(11.8 \%)$ & $64(11.9 \%)$ & $4(9.3 \%)$ & $21(12.2 \%)$ \\
\hline Fluoroquinolones & $48(6.4 \%)$ & $35(6.5 \%)$ & $1(2.3 \%)$ & $12(7 \%)$ \\
\hline Glycopeptides & $16(2.1 \%)$ & $11(2 \%)$ & $1(2.3 \%)$ & $4(2.3 \%)$ \\
\hline First-generation cephalosporins & $16(2.1 \%)$ & $9(1.7 \%)$ & $1(2.3 \%)$ & $6(3.5 \%)$ \\
\hline Second-generation cephalosporins & $13(1.7 \%)$ & $8(1.5 \%)$ & $1(2.3 \%)$ & $4(2.3 \%)$ \\
\hline Fourth-generation cephalosporins & $12(1.6 \%)$ & $9(1.7 \%)$ & $1(2.3 \%)$ & $2(1.2 \%)$ \\
\hline Tetracyclines & $6(0.8 \%)$ & $2(0.4 \%)$ & 0 & $4(2.3 \%)$ \\
\hline Combination therapy—top 10 & $n=742$ & $n=396$ & $n=197$ & $n=149$ \\
\hline Glycopeptides & $242(32.6 \%)$ & $134(33.8 \%)$ & $71(36 \%)$ & $37(24.8 \%)$ \\
\hline Carbapenems & $230(31 \%)$ & $136(34.3 \%)$ & $53(26.9 \%)$ & $41(27.5 \%)$ \\
\hline $\begin{array}{l}\text { Antipseudomonal penicillins }+\beta \text {-lactamase } \\
\text { inhibitor }\end{array}$ & $208(28 \%)$ & $100(25.3 \%)$ & $73(37.1 \%)$ & $35(23.5 \%)$ \\
\hline Third-generation cephalosporins & $200(27 \%)$ & $106(26.8 \%)$ & $53(26.9 \%)$ & $41(27.5 \%)$ \\
\hline Macrolides & 114 (15.4\%) & 49 (12.4\%) & 41 (20.8\%) & 24 (16.1\%) \\
\hline
\end{tabular}


Table 3 (continued)

\begin{tabular}{|c|c|c|c|c|}
\hline Combination therapy-top 10 & $n=742$ & $n=396$ & $n=197$ & $n=149$ \\
\hline Aminoglycosides & $107(14.4 \%)$ & $37(9.3 \%)$ & $52(26.4 \%)$ & $18(12.1 \%)$ \\
\hline Fluoroquinolones & 105 (14.2\%) & $54(13.6 \%)$ & $25(12.7 \%)$ & $26(17.4 \%)$ \\
\hline Nitroimidazoles & $84(11.3 \%)$ & 41 (10.4\%) & $21(10.7 \%)$ & $22(14.8 \%)$ \\
\hline Penicillins $+\beta$-lactamase inhibitor & $72(9.7 \%)$ & $36(9.1 \%)$ & $20(10.2 \%)$ & $16(10.7 \%)$ \\
\hline Clindamycin & $72(9.7 \%)$ & $46(11.6 \%)$ & $12(6.1 \%)$ & $14(9.4 \%)$ \\
\hline
\end{tabular}

were comparable in both treatment groups. Both median number ICU and hospital days were smaller in ADE than in "no change" patients [7 days (IQR 4-12) vs. 9 days (IQR 5-19); $p<0.001$ and 19 days (IQR 10-28) vs. 27 days (IQR 14-28); $p<0.001$, respectively]. Mortality at day 28 was $15.8 \%$ in ADE and $19.4 \%$ in "no change" patients (RR $0.83(0.6-1.14) ; p=0.27$,). Details on patient outcome are described in Table 5.

\section{Analysis of clinical cure in ADE patients using inverse probability weighting}

The estimated relative risk of survival and clinical cure, survival without clinical cure and mortality on day 7 in ADE patients versus patients in whom ADE was not performed on day 3 or earlier were 1.37 (95\% CI 1.14-1.64), 0.66 (95\% CI 0.47-0.92) and 1.32 (95\% CI 0.95-1.83), respectively. IP weighted risks and detailed results of subgroup and sensitivity analyses can be found in online supplement 11. Post hoc power and sample size calculations are available in online supplement 12.

\section{Discussion}

In this study, investigating empirical antimicrobial therapy for patients with bacterial infections in the ICU, we found that ADE was infrequently applied, despite the fact that combination therapy was prescribed in half of the patients and one-quarter of prescriptions contained a carbapenem. Our observational effect estimate of ADE on clinical cure suggested that ADE performed within 3 days following empirical prescription was not worse compared to no-ADE after adjustment for potential bias and confounding. However, residual confounding remains possible.

Previous studies reported ADE rates between 25 and $81 \%$ [4,34]. Studies with higher percentages of ADE often included patients with lower severity of illness compared to our study or focused on patients in whom ADE was possible due to the broadness of the empirical spectrum and the susceptibility pattern of the causative pathogens $[4,35]$. Other studies included only patients with specific types of infections or pathogens [36-38]. These were usually single-center studies, conducted in centers with a special interest in antimicrobial stewardship. Instead, we studied ICU patients and included all empirical antimicrobial therapies, independent of culture results, and therefore provide a more realistic picture of ADE in routine clinical practice.

\section{Table 4 Motivation for ADE}

Replacement of an antimicrobial agent by another drug with the intention to narrow the spectrum of activity (115 ADE treatment courses) (multiple answers possible)

\begin{tabular}{lc} 
Gram's stain results & $13 / 115(11.3)$ \\
Rapid polymerase chain reaction technology & $3 / 115(2.6)$ \\
\hline Identification of the causative pathogen & $67 / 115(58.3)$ \\
Susceptibility pattern of the causative pathogen & $54 / 115(47)$ \\
Negative culture results & $10 / 115(8.7)$ \\
Improvement in organ function & $14 / 115(12.2)$ \\
Improvement in inflammation biomarkers & $11 / 115(9.6)$ \\
Better compliance with local guidelines & $11 / 115(9.6)$
\end{tabular}

Discontinuation of one or more antimicrobials of the empirical combination therapy which were considered by the treating physician to be not (or no longer) necessary

(156 ADE treatment courses) (only one answer possible)

In case of microbiologically confirmed infection, causative pathogen is covered by concomitant antimicrobial therapy $67 / 156(42.9)$ In case of microbiologically confirmed infection, causative pathogen(s) is not covered by this antibacterial or antifungal agent $30 / 156(19.2)$ In case of non-microbiologically confirmed infection, this antibacterial or antifungal agent is considered not to be essential $65 / 156(41.7)$

$A D E$ antimicrobial de-escalation 
Another explanation for the lower than expected ADE rate could be the strict definition of ADE that was used, i.e., ADE applied within the first 3 days of initiation of empirical therapy. Previous studies defined timing of ADE in various ways, e.g., within 3 or 5 days following treatment initiation, or aligned with the timing of microbiology results [15, 36, 37, 39-45]. Expanding the ADE time-window to 5 and 7 days would have increased the ADE rate to $21 \%$ and $23 \%$, respectively.

Our pragmatic approach of defining ADE based on the intention of the treating clinician to narrow the antimicrobial spectrum was a carefully considered decision. Until now, there is no consensus regarding the hierarchy of antimicrobials and although there have been proposals for ranking antimicrobials, for instance within certain classes, e.g., beta-lactam antibiotics, this is difficult-if not impossible-to apply to all antimicrobials [33, 46]. We observed that $91 \%$ of the de-escalated beta-lactam prescriptions in our dataset complied with the ranking developed by Weiss et al. [33]. However, within the ADE population, this ranking definition was only applicable in $31 \%$.

Clinical cure on day 7 in patients following ADE has not been studied before. We attempted to control for potential confounding and performed multiple sensitivity analyses (e.g. adjustment for SOFA day 0, inappropriate empirical therapy and MDR colonization) which did not significantly affect our results. We have to acknowledge however that our data are observational and it is therefore impossible to capture all center, physician, patient and infection-related factors that may impact both treatment-related decision making and our primary outcome. Particular factors related to empirical treatment and infection characteristics appeared to facilitate ADE, e.g., 2 or more empirical agents, adequate empirical prescription, effective source control, improving SOFA scores on day 3 and the detection of causative pathogens to guide ADE. Previous observations indicate that ADE is undertaken more often in patients with an already favorable clinical course, e.g., improving SOFA score, a phenomenon that was also observed in our study [4]. Early clinical improvement may also explain the shorter lengths of stay which we observed in ADE patients compared to patients with no treatment change, a finding that has been inconsistently documented in previous studies and is in contradiction with the results of Leone et al. $[4,15,34,37$, $39-41,44]$. In contrast to several studies in the literature, we found no difference in mortality between the ADE and "no change" patients $[4,13,14]$. Again, it is generally assumed that ADE is typically performed in patients who are improving or have a good prognosis; therefore, the survival advantage reported in the literature cannot be considered a direct causal effect.
The impact of ADE on MDR emergence has been investigated sparsely and no study has found an association between $\mathrm{ADE}$ and MDR occurrence in either direction [15, 34, 41, 44]. We could not demonstrate any difference in the emergence of MDR pathogens following ADE; however, our study was not designed to make firm conclusions about this aspect.

The strengths of the study include the number of patients and the global perspective. With data of 152 centers worldwide, we provide a detailed picture of the practice of ADE as a stewardship intervention in real-life situations.

The limitations of the study are the heterogeneous patient population in terms of geography, types of infections and methods of antimicrobial stewardship. In addition, individual centers only included a limited number of patients over a short-time period. Details on the reasons for not performing ADE were not collected in a prospective way; as such, an explanation for the observed low $\mathrm{ADE}$ rate cannot be given. Study design was complicated by the lack of a universally accepted ADE definition. The low quality of evidence supporting the recent ESICM/ ESCMID consensus definition of ADE underlines the ongoing controversy [7]. Our definition was reached by consensus and intended to capture real-world practices. As mentioned earlier, expanding the ADE time window to 5 or 7 days would have increased the ADE rate. A priori sample size calculations were complicated by the lack of clinical cure rates in the literature and by the fact that standard sample size formulas do not readily apply to observational analyses that adjust for confounding. Our post hoc analyses, however, may be informative for the planning of future studies, either observational or randomized. Maximal efforts were undertaken to reduce bias by using appropriate statistical methods in terms of target trial emulation. However, it was not possible to determine the exact time when the treating clinicians received information about causative microbiology and acted upon this. Therefore, we made the assumption that this information was available from day 2 . Similarly, susceptibility patterns of the causative pathogens could not be included in the outcome analysis. Considering the aforementioned reasons, residual confounding may exist. Finally, clinical cure was evaluated quite early in the clinical course of the ICU patient (day 7) and our analyses do not permit any statements regarding other important outcome measures such as, e.g., infection relapse.

In conclusion, this study showed that ADE within the first 3 days following empirical antimicrobial therapy for suspected bacterial infection in the ICU is only applied in $16 \%$ of patients. Our observational effect estimate of $\mathrm{ADE}-$ as it was applied and defined in the study 
Table 5 Patient outcome

\begin{tabular}{|c|c|c|c|c|c|c|c|c|c|}
\hline & $\begin{array}{l}\text { Total } \\
n=1495\end{array}$ & $\begin{array}{l}\text { No change } \\
n=934 ; 62.5 \%\end{array}$ & $\begin{array}{l}\text { ADE } \\
n=240 ; 16.1 \%\end{array}$ & $\begin{array}{l}\text { Other change } \\
n=321 ; 21.5 \%\end{array}$ & \multicolumn{2}{|c|}{$\begin{array}{l}\text { ADE vs no change } \\
p \text { value }\end{array}$} & \multicolumn{2}{|c|}{$\begin{array}{l}\text { Other change vs no change } \\
p \text { value }\end{array}$} & $\begin{array}{l}\text { \% of avail- } \\
\text { able data }\end{array}$ \\
\hline$\triangle$ SOFA $^{\mathrm{a}, \mathrm{b}}$ & $1[0-3]$ & $1[0-3]$ & $2[0-4]$ & $0[-1 ; 2]$ & \multicolumn{2}{|l|}{$<0.001$} & \multicolumn{2}{|l|}{$<0.001$} & 90 \\
\hline \multicolumn{10}{|c|}{ Number of days in the $I^{C} U^{c}$} \\
\hline On vasoactive drugs & $2[0-5]$ & $2[0-5]$ & $2[0-4]$ & $3[0-5]$ & \multicolumn{2}{|l|}{0.32} & \multicolumn{2}{|l|}{0.003} & 98.3 \\
\hline $\begin{array}{l}\text { On invasive mechani- } \\
\text { cal ventilation }\end{array}$ & $3[0-9]$ & $3[0-9]$ & $2[0-8]$ & $4[0-9]$ & \multicolumn{2}{|l|}{0.05} & \multicolumn{2}{|l|}{0.31} & 98.4 \\
\hline $\begin{array}{l}\text { Receiving renal } \\
\text { replacement } \\
\text { therapy }\end{array}$ & $0[0-0]$ & $0[0-0]$ & $0[0-0]$ & $0[0-0]$ & \multicolumn{2}{|l|}{0.48} & \multicolumn{2}{|l|}{0.002} & 98.5 \\
\hline $\begin{array}{l}\text { Antimicrobial-free } \\
\text { days ( } 28 \text { days after } \\
\text { onset of infection) } \\
(n=1166)\end{array}$ & 13 [4-19] & $13[4-20]$ & $14[5-20]$ & $9.5[2-16]$ & \multicolumn{2}{|l|}{0.29} & \multicolumn{2}{|l|}{$<0.001$} & 85.5 \\
\hline $\begin{array}{l}\text { Number of days in } \\
\text { ICU following onset } \\
\text { of infection under } \\
\text { study }^{c, e}(n=1219)\end{array}$ & $8[5-18]$ & $9[5-19]$ & $7[4-12]$ & $10[5-24]$ & \multicolumn{2}{|l|}{$<0.001$} & \multicolumn{2}{|l|}{0.09} & 99.9 \\
\hline \multirow{2}{*}{$\begin{array}{l}\text { Number of days in hos- } \\
\text { pital following onset } \\
\text { of infection under } \\
\text { study }{ }^{c, f}(n=1166)\end{array}$} & 26 [13-28] & 27 [14-28] & 19 [10-28] & 28 [16-28] & \multicolumn{2}{|l|}{$<0.001$} & \multicolumn{2}{|l|}{0.26} & 99.9 \\
\hline & & & & & $p$ value & $\begin{array}{l}\text { Relative risk } \\
(95 \% \mathrm{Cl})\end{array}$ & $p$ value & $\begin{array}{l}\text { Relative risk } \\
(95 \% \mathrm{Cl})\end{array}$ & \\
\hline Clinical cure on day $7^{g}$ & $650(43.5 \%)$ & $399(42.7 \%)$ & $139(57.9 \%)$ & $112(34.9 \%)$ & $<0.001$ & $1.34(1.18-1.52)$ & 0.03 & $0.83(0.71-0.98)$ & 95.9 \\
\hline Infection relapse ${ }^{(c)}$ & $103(6.9 \%)$ & $61(6.5 \%)$ & $22(9.2 \%)$ & $20(6.2 \%)$ & 0.24 & $1.37(0.86-2.18)$ & 0.96 & $0.96(0.59-1.56)$ & 96.5 \\
\hline $\begin{array}{l}\text { Infections other than } \\
\text { the infection under } \\
\text { study or a relapse } \\
\text { infection }\end{array}$ & $184(12.3 \%)$ & 109 (11.7\%) & $38(15.8 \%)$ & $37(11.5 \%)$ & 0.12 & $1.34(0.95-1.89)$ & 1 & $0.99(0.69-1.40)$ & 95.5 \\
\hline $\begin{array}{l}\text { Emergence of MDR } \\
\text { pathogens between } \\
\text { day } 2 \text { and day } 28^{\mathrm{h}}\end{array}$ & $192(12.8 \%)$ & $111(11.9 \%)$ & $18(7.5 \%)$ & $63(19.6 \%)$ & 0.06 & $0.63(0.39-1.01)$ & 0.001 & $1.63(1.23-2.16)$ & 98.7 \\
\hline 28-day mortality & 296 (19.8\%) & 181 (19.4\%) & $38(15.8 \%)$ & 77 (24\%) & 0.27 & $0.83(0.60-1.14)$ & 0.07 & $1.26(0.99-1.59)$ & 97.8 \\
\hline ICU mortality & $243(16.3 \%)$ & 145 (15.5\%) & $28(11.7 \%)$ & 70 (21.8\%) & 0.18 & $0.76(0.52-1.11)$ & 0.009 & $1.42(1.10-1.84)$ & 97.8 \\
\hline
\end{tabular}

Results are shown as $n$ (\%) or median [IQR] where applicable. $A D E$ antimicrobial de-escalation, ICU intensive care unit, $M D R$ multidrug-resistant

a In subgroup of patients alive at day $3, n=1420$

b $\triangle$ SOFA is SOFA score on day 0 minus SOFA score on day 3 of infection

c Measured from inclusion (day 0 ) to day 28

$d$ In subgroup of patients alive at day 28

e In subgroup of ICU survivors

${ }^{f}$ In subgroup of hospital survivors

9 Clinical cure is defined as survival and resolution of all signs and symptoms related to the infection under study

${ }^{h}$ MDR definitions are available in the Supplement (eTable 3), Emergence of MDR following the initiation of empirical treatment was defined as detection of MDR pathogens on day 2 or later during the 28 -day follow-up period and not present before

population-on clinical cure suggested that ADE was not worse compared with no-ADE. As ADE was mainly performed in patients who were improving clinically, residual confounding by unmeasured factors cannot be ruled out.

Concerted efforts based on specific patient, infection and microbiology-related data and guided by an antimicrobial stewardship team are likely needed to promote ADE. Further research focusing on antimicrobial prescribing behavior is however required to elucidate barriers to ADE.

\section{Electronic supplementary material}

The online version of this article (https://doi.org/10.1007/s00134-020-06111-5) contains supplementary material, which is available to authorized users.

\section{DIANA study group-study collaborators:}

Fernando Rios (Sanatorio Las Lomas, Buenos Aires, Argentina), Alejandro Risso Vazquez (Otamendi and Miroli Sanatorium, Buenos Aires, Argentina), Maria Gabriela Vidal (Hospital Interzonal de Agudos San Martin de La Plata, La Plata, Buenos Aires, Argentina), Graciela Zakalik (Luis C. Lagomaggiore Hospital, Mendoza, Argentina), Antony George Attokaran (Rockhampton Hospital, Rockhampton, Australia), louri Banakh (Frankston Hospital Peninsula Health, Frankston, Victoria, Australia), Smita Dey-Chatterjee (St John of God Hospital Murdoch, Murdoch, Australia), Julie Ewan (St John of God Subiaco Hospital, Subiaco, Australia), Janet Ferrier (St John of God Subiaco Hospital, Subiaco, Australia), Loretta Forbes (Sunshine Coast University Hospital, Brisbane, 
Australia), Cheryl Fourie (Royal Brisbane and Women's Hospital, Herston Brisbane, Australia), Anne Leditschke (Mater Hospital Brisbane, Brisbane, Australia), Lauren Murray (Sunshine Coast University Hospital, Brisbane, Australia), Philipp Eller (University Hospital Graz, Graz, Austria), Patrick Biston (CHU de Charleroi, Charleroi, Belgium), Stephanie Bracke (Ghent University Hospital, Ghent, Belgium), Luc De Crop (Ghent University Hospital, Ghent, Belgium), Nicolas De Schryver (Clinique Saint Pierre Ottignies, Ottignies-Louvain-la-Neuve, Belgium), Eric Frans (Imelda Hospital, Bonheiden, Belgium), Herbert Spapen (Universitair Ziekenhuis Brussel, Brussel, Belgium), Claire Van Malderen (Universitair Ziekenhuis Brussel, Brussel, Belgium), Stijn Vansteelandt (Department of Applied Mathematics, Computer Science and Statistics, Ghent University, Ghent, Belgium; Department of Medical Statistics, London School of Hygiene and Tropical Medicine, London, United Kingdom), Daisy Vermeiren (Ghent University Hospital, Ghent, Belgium), Elias Pablo Arévalo (Hospital Dr. Jaime Mendoza, Sucre, Bolivia), Mónica Crespo (Hospital Universitario Japonés Santa Cruz, Santa Cruz de la Sierra, Bolivia), Roberto Zelaya Flores (Hospital General San Juan de Dios, Oruro, Bolivia), Petr Píza (IKEM Transplant Centre, Prague, Czech Republic), Diego Morocho Tutillo (Hospital de Especialidades Eugenio Espejo, Quito, Ecuador), Andreas Elme (North Estonia Medical Centre, Tallinn, Estonia), Anne Kallaste (Tartu University Hospital, Tartu, Estonia), Joel Starkopf (Tartu University Hospital, Tartu, Estonia), Jeremy Bourenne (Hôpital de la Timone, Marseille, France), Mathieu Calypso (Hôpital Nord Marseille, Marseille, France), Yves Cohen (Hôpital Avicenne, Bobigny, France), Claire Dahyot-Fizelier (CHU de Poitiers, Poitiers, France), François Depret (Hôpital Saint-Louis, Paris, France), Max Guillot (Hôpitaux Universitaires de Strasbourg, Strasbourg, France), Nadia Imzi (CHU de Poitiers, Poitiers, France), Sebastien Jochmans (Melun Hospital France, Melun, France), Achille Kouatchet (CHU D'Angers, Angers, France), Alain Lepape (CHU Lyon Sud, Lyon, France), Olivier Martin (Hôpital Avicenne, Bobigny, France), Markus Heim (Klinikum rechts der Isar Munich IS2, Munich, Germany), Stefan J Schaller (Klinikum rechts der Isar Munich IS1, Munich, Germany), Kostoula Arvaniti (Papageorgiou Hospital, Thessaloniki, Greece), Anestis Bekridelis (General Hospital of Katerini, Katerini, Greece), Panagiotis loannidis (General Hospital of Katerini, Katerini, Greece), Cornelia Mitrakos (Attikon University General Hospital, Athens, Greece), Metaxia N. Papanikolaou (Hippocrateion General Hospital of Athens, Athens, Greece), Sofia Pouriki (Hippocrateion General Hospital of Athens, Athens, Greece), Anna Vemvetsou (Papageorgiou Hospital, Thessaloniki, Greece), Babu Abraham (Apollo Hospitals, Chennai, Tamil Nadu, India), Pradip Kumar Bhattacharya (Chirayu Medical College Hospital, Bhopal, India), Anusha Budugu (Apollo Hospitals Jubilee Hills, Hyderabad, India), Subhal Dixit (Sanjeevan hospital, Pune, India), Sushma Gurav (Grant medical foundation Ruby hall clinic, Pune, India), Padmaja Kandanuri (Apollo Hospitals Jubilee Hills, Hyderabad, India), Dattatray Arun Prabhu (Kasturba Medical College, Mangalore, India), Darshana Rathod (Sir Hurkisondas Reliance Foundation Hospital, Mumbai, India), Kavitha Savaru (Kasturba Medical college hospital, Manipal, India), Ashwin Neelavar Udupa (Kasturba Medical college hospital, Manipal, India), Sunitha Binu Varghese (Niramay hospital Pimpri, Pune, India), Hossein Haddad Bakhodaei (Nemazee Hospital, Neurosurgical ICU, Shiraz, Iran), Gholamreza Dabiri (Rajaee Hospital, Trauma ICU (6), Shiraz, Iran), Mohammad Javad Fallahi (Nemazee Hospital, Medical ICU, Shiraz, Iran), Farnia Feiz (Faghihi Hospital, Shiraz, Iran), Mohammad Firoozifar (Nemazee Hospital, Post-transplant ICU, Shiraz, Iran), Vahid Khaloo (Aliasghar Hospital, Shiraz, Iran), Behzad Maghsudi (Nemazee Hospital, Central ICU, Shiraz, Iran), Mansoor Masjedi (Rajaee Hospital, Trauma ICU (3), Shiraz, Iran), Reza Nikandish (Nemazee Hospital, Emergency ICU, Shiraz, Iran), Golnar Sabetian (Rajaee Hospital, Trauma ICU (4), Shiraz, Iran), Brian Marsh (Misericordiae University Hospital, Dublin, Ireland), Ignacio Martin-Loeches (St James's Hospital, Dublin, Ireland), Jan Steiner (Galway Clinic Doughiska, Galway, Ireland), Maria Barbagallo (UO 2 Anestesia Rianimazione Terapia Antalgica Azienda Ospedaliero-Universitaria di Parma, Parma, Italy), Anselmo Caricato (Terapia Intensiva Neurochirurgica Fondazione Policlinico Universitario "A. Gemelli" IRCCS Rome, Rome, Italy), Andrea Cortegiani (Policlinico Paolo Giaccone. University of Palermo, Palermo, Italy), Rocco D'Andrea (University Hospital Sant'Orsola Malpighi Bologna, Bologna, Italy), Cristian Deana (Academic Hospital "Santa Maria della Misericordia" Udine, Udine, Italy), Abele Donati (Clinica di Anestesia e Rianimazione Ospedali Riuniti di Ancona, Ancona, Italy), Massimo Girardis (University Hospital of Modena, Modena, Italy), Giuliana Mandalà (ARNAS Civico Palermo, Palermo, Italy), Giovanna Panarello (Ismett UPMC Palermo, Palermo, Italy), Daniela Pasero (AOU Città della Salute e della Scienza Turin, Turin, Italy), Lorella Pelagalli (National Cancer Institute of Rome "Regina Elena", Rome, Italy), Paolo Maurizio Soave (UOC Rianimazione, Terapia
Intensiva e Tossicologia Clinica Fondazione Policlinico Universitario Agostino Gemelli IRCCS Rome, Rome, Italy), Savino Spadaro (Arcispedale Sant' Anna Ferrara, Ferrara, Italy), Yoshihito Fujita (Aichi Medical University Hospital, Nagakute, Japan), Shinsuke Fujiwara (NHO Ureshino Medical Center, Ureshino, Japan), Yuya Hara (Yodogawa Christian Hospital, Toyonaka, Japan), Hideki Hashi (Tokyo Bay Urayasu Ichikawa Medical Center, Urayasu-city, Japan), Satoru Hashimoto (University Hospital, Kyoto Prefectural University of Medicine, Kyoto, Japan), Hideki Hashimoto (Hitachi General Hospital, Hitachi, Japan), Katsura Hayakawa (Saitama Red Cross Hospital, Shintoshin, Japan), Masashi Inoue (Nagoya City University Hospital, Nagoya-shi, Japan), Shutaro Isokawa (St.Luke's International Hospital, Tyuouku, Japan), Shinya Kameda (Jikei University School of Medicine Hospital, Minato City, Japan), Hidenobu Kamohara (Kumamoto University Hospital, Kumamoto, Japan), Masafumi Kanamoto (Gunma University Hospital, Maebashi-shi, Japan), Shinshu Katayama (Jichi Medical University Hospital, Tochigi, Japan), Toshiomi Kawagishi (Jichi Medical University Saitama Medical Center, Saitama-shi, Japan), Yasumasa Kawano (Fukuoka University Hospital, Fukuoka, Japan), Yoshiko Kida (Hiroshima University Hospital, Hiroshima city, Japan), Mami Kita (Wakayama Medical University Hospital, Wakayama, Japan), Atsuko Kobayashi (Takarazuka City Hospital, Takarazuka, Japan), Akira Kuriyama (Kurashiki Central Hospital, Kurashiki, Japan), Takaki Naito (Nerima Hikarigaoka Hospital, Nerima, Japan), Hiroshi Nashiki (Iwate Prefectural Central Hospital, Morioka, Japan), Kei Nishiyama (Kyoto Medical Center, Kyoto, Japan), Shunsuke Shindo (Saiseikai Yokohamashi Tobu Hospital, Yokohama, Japan), Taketo Suzuki (Yokohama City Minato Red Cross Hospital, Yokohama, Japan), Akihiro Takaba (JA Hiroshima General Hospital, Hatsukaichi, Japan), Chie Tanaka (Nippon Medical School Tama Nagayama Hospital, Tokyo, Japan), Komuro Tetsuya (Shonan Kamakura General Hospital, Kamakura, Japan), Yoshihiro Tomioka (Ota Memorial Hospital, Ohta, Japan), Youichi Yanagawa (Shizuoka Hospital, Juntendo University, Izunokuni, Japan), Hideki Yoshida (St marianna University Seibu municipal hospital, Yokohama, Japan), Syamhanin Adnan (Hospital Sungai Buloh, Selangor, Malaysia), Mohd Shahnaz Hasan (University Malaya Medical Centre, Kuala Lumpur, Malaysia), Helmi Sulaiman (Faculty of Medicine, University of Malaya, Kuala Lumpur, Malaysia), Gilberto A. Gasca Lopez (Hospital regional de alta especialidad de Ixtapaluca, Ixtapaluca, Mexico), Carmen M. HernándezCárdenas (Instituto Nacional de Enfermedades Resporatorias Ismael Cosio Villegas, Mexico City, Mexico), Silvio A. Ñamendys-Silva (Fundacion Clinica Medica Sur, Mexico City, Mexico), Carina Bethlehem (Tjongerschans Ziekenhuis, Heerenveen, Netherlands), Dylan de Lange (University Medical Center Utrecht, Utrecht, Netherlands), Nicole Hunfeld (ErasmusMC University Medical Center, Rotterdam, Netherlands), Sandra Numan (University Medical Center Utrecht, Utrecht, Netherlands), Henk van Leeuwen (Rijnstate Arnhem, Arnhem, Netherlands), Daniel Owens (Whangarei Base Hospital, Whangarei, New Zealand), Mónica Almeida (Centro Hospitalar do Porto, Porto, Portugal), Elsa Fragoso (Hospital de Santa Maria, Lisboa, Portugal), Tiago Leonor (Centro Hospitalar Entre Douro e Vouga, Hospital de São Sebastião, Santa Maria da Feira, Portugal), José-Manuel Pereira (Centro Hospitalar São João-ICU Polivalente da Urgência, Porto, Portugal), Daniela Filipescu (Institute for Cardiovascular Diseases C.C. Iliescu Bucharest, Bucharest, Romania), loana Grigoras (Regional Instiute of Oncology lasi, lasi, Romania), Mihai Popescu (Fundeni Clinical Institute Bucharest, Bucharest, Romania), DanaTomescu (Department of Anesthesiology and Intensive Care, Fundeni Clinical Institute, Bucharest, Romania), Mohammed S. Alshahrani (King Fahd university Hospital, Al Khobar, Saudi Arabia), Manuel Alvarez-Gonzalez (Hospital Universitario Clinico San Carlos Madrid Neurotrauma, Madrid, Spain), Irene Barrero-García (Hospital Universitario Virgen Macarena, Sevila, Spain), Miguel Angel Blasco-Navalpotro (Hospital Universitario Severo Ochoa, Leganés (Madrid), Spain), Laura Claverias (Hospital Verge de la cinta Tortosa, Tortosa, Spain), Ángel Estella (University Hospital SAS de Jerez, Jerez de la Frontera, Spain), Lorena Forcelledo Espina (Hospital Universitario Central de Asturias, Oviedo, Spain), Jose Luis Garcia Garmendia (Hospital San Juan de Dios del Aljarafe, Bormujos, Spain), Emilio García Prieto (Hospital Universitario Central de Asturias, Oviedo, Spain), Gracia Gómez-Prieto (Hospital Universitario Virgen Macarena, Sevila, Spain), Carlos Jiménez Conde (Hospital Juan Ramón Jiménez de Huelva, Huelva, Spain), Fernando Martinez Sagasti (Hospital Universitario Clinico San Carlos Madrid Medical, Madrid, Spain), Alicia Muñoz Cantero (Hospital Universitario de Badajoz, Badajoz, Spain), Alberto Orejas-Gallego (Hospital Universitario Severo Ochoa, Leganés (Madrid), Spain), Elisabeth Papiol (Vall d'Hebron Hospital, Barcelona, Spain), Demetrio Pérez-Civantos (Hospital Universitario de Badajoz, Badajoz, Spain), Juan Carlos Pozo Laderas (Reina Sofía University Hospital Córdoba, Cordoba, Spain), Josep Trenado 
Álvarez (Hospital Universitario Mútua Terrassa, Terrassa, Spain), Paula Vera-Artázcoz (Hospital de la Santa Creu i Sant Pau, Barcelona, Spain), Pablo Vidal Cortés (CHU Ourense, Ourense, Spain), Anders Oldner (Karolinska University Hospital Solna Stockholm, Stockholm, Sweden), Martin Spångfors (Hospital of Kristianstad, Kristianstad, Sweden), Emine Alp (Erciyes Üniversitesi Tıp Fakültesi Infeksiyon Hastalıkları ve Klinik Mikrobiyoloji Anabilimdalı, Kayseri, Turkey), Iftihar Köksal (Karadeniz Teknik Üniversitesi Hastanesi Infeksiyon Hastalıkları, Trabzon, Turkey), Volkan Korten (Marmara Üniversitesi Tıp Fakültesi Infeksiyon Hastalıkları Anabilimdalı, Marmara, Turkey), Arife Özveren (Hacettepe Ün. Hospital İnfectious Diseases, Ankara, Turkey), Anna Hall (Guy's and St Thomas' Hospital, London, United Kingdom), Kevin W. Hatton (University of Kentucky, Lexington, Kentucky, United States), Krzysztof Laudanski (Hospital of the University of Pennsylvania, Philadelphia, United States)

\section{Author details}

${ }^{1}$ Department of Critical Care Medicine, Ghent University Hospital, C. Heymanslaan 10, 9000 Ghent, Belgium. ${ }^{2}$ Heymans Institute of Pharmacology, Ghent University, Ghent, Belgium. ${ }^{3}$ Department of Internal Medicine and Pediatrics, Ghent University Hospital, C. Heymanslaan 10, Ghent, Belgium. ${ }^{4}$ Renal Division, Ghent University Hospital, C. Heymanslaan 10, Ghent, Belgium. ${ }^{5}$ Intensive Care Unit, Redcliffe and Caboolture Hospitals, Brisbane, QLD, Australia. ${ }^{6}$ Faculty of Medicine, University of Queensland, Brisbane, QLD, Australia. ${ }^{7}$ Departmant of Infectious Diseases and Clinical Microbiology, Hacettepe University School of Medicine, Ankara, Turkey. ${ }^{8}$ Centre for Translational Anti-Infective Pharmacodynamics, School of Pharmacy, The University of Queensland, Brisbane, Australia. ${ }^{9}$ University of Queensland Centre of Clinical Research, Faculty of Medicine, The University of Queensland, Brisbane, QLD, Australia. ${ }^{10}$ Dipartimento Di Scienza Dell'Emergenza, Anestesiologiche e della Rianimazione - UOC Di Anestesia, Rianimazione, Terapia Intensiva e Tossicologia Clinica - Istituto di Anestesia e Rianimazione, Fondazione Policlinico Universitario A. Gemelli IRCCS, Rome, Italy. ${ }^{11}$ Università Cattolica del Sacro Cuore, Rome, Italy. ${ }^{12}$ Department of Critical Care, University Hospital Attikon, Athens, Greece. ${ }^{13}$ Medical School, National and Kapodistrian University of Athens, Athens, Greece. ${ }^{14}$ Emergency Medicine and Critical Care Medicine, St. Marianna University Hospital, Kawasaki-City, Kanagawa, Japan. ${ }^{15}$ Intensive Care Clinical Unit, Hospital Universitario Virgen Macarena, Seville, Spain. ${ }^{16}$ Instituto de Biomedicina de Sevilla (IBIS), Seville, Spain. ${ }^{17}$ Service d'Anesthésie et de Réanimation, Hôpital NordAssistance Publique Hôpitaux de Marseille, Aix-Marseille Université, Marseille, France. ${ }^{18}$ Department of Intensive Care Medicine, Royal Brisbane and Women's Hospital, Brisbane, QLD, Australia. ${ }^{19}$ Division of Anaesthesiology Critical Care Emergency and Pain Medicine, Nimes University Hospital, University of Montpellier, Nîmes, France. ${ }^{20}$ Department of Critical Care, King's College London, Guy's and St Thomas' Hospital, London, UK. ${ }^{21}$ Emergency and Intensive Care Department, Centro Hospitalar Universitário São João EPE, Porto, Portugal. ${ }^{22}$ Faculdade de Medicina da Universidade Do Porto, Grupo de Infecção E Sépsis, Porto, Portugal. ${ }^{23}$ Department of Intensive Care Medicine, Radboud University Medical Center, Nijmegen, The Netherlands.

${ }^{24}$ Scientific Center for Quality of Healthcare, IQ Healthcare, Radboud University Medical Center, Nijmegen, The Netherlands. ${ }^{25}$ Department of Intensive Care and Perioperative Medicine, Skane University Hospital, Malmö, Sweden. ${ }^{26}$ Mitochondrial Medicine, Lund University, Lund, Sweden. ${ }^{27}$ Sorbonne Paris Cité, IAME, UMR 1137, Université de Paris, Paris, France. ${ }^{28}$ Medical and Infectious Diseases Intensive Care Unit, AP-HP, Bichat-Claude Bernard Hospital, 75018 Paris, France. ${ }^{29}$ Department of Pharmacy, Royal Brisbane and Women's Hospital, Brisbane, QLD, Australia. ${ }^{30}$ INSERM, IAME UMR 1137, University of Paris, Paris, France. ${ }^{31}$ Microbiology, Infection Control Unit, GH Paris Seine Saint-Denis, APHP, Bobigny, France. ${ }^{32}$ Shiraz Anesthesiology and Critical Care Research Center, Shiraz University of Medical Sciences, Shiraz, Iran. ${ }^{33}$ Grant Medical Foundation, Ruby Hall Clinic, Pune, Maharashtra, India.

\section{Author contributions}

Conception and design of the study (Liesbet De Bus, Jan J De Waele, Pieter Depuydt, George Dimopoulos, Jose Garnacho-Montero, Marc Leone, Jeffrey Lipman, José Artur Paiva, Jason Roberts, Jeroen Schouten, Alexis Tabah, JeanFrançois Timsit, Jean Ralph Zahar). Substantial contribution to data acquisition (Liesbet De Bus, Jan J De Waele, Murat Akova, Menino Osbert Cotta, Gennaro De Pascale, Ken De Smet, Shigeki Fujitani, Jose Garnacho-Montero, Marc Leone, Marlies Ostermann, José Artur Paiva, Jeroen Schouten, Fredrik Sjovall, Farid Zand, Kapil Zirpe). Design and execution of statistical analysis and data interpretation (Liesbet De Bus, Jan J De Waele, Pieter Depuydt, Sofie Dhaese, Johan Steen, Alexis Tabah). Writing_original draft preparation (Liesbet De Bus, Jan J De Waele, Pieter Depuydt). All authors critically revised and commented on previous versions of the manuscript. All authors read and approved the final manuscript.

\section{Funding}

The DIANA study was not funded.

\section{Compliance with ethical standards}

\section{Conflicts of interest}

LDB, PD, SD, KDS, JSteen, AT, MA, MOC, GDP, GD, SF, JGM, JAP, JSchouten, FS, FZ, KZ have no conflicts of interest to declare. ML: consulting Amomed, Aguettant; lectures MSD, Pfizer, 3 M, Aspen, Orion, 3 M, Edwards. JL: board membership: Bayer ESICM Advisory Board, MSD Antibacterials Advisory Board; honorarium for lectures: Pfizer South Africa, MSD South Africa; committee: Pfizer International: 2018 Anti-Infectives. MO: speaker honoraria Fresenius Medical, Baxter and Biomerieux; research funding from Fresenius Medical, Baxter and LaJolla Pharma; member of an advisory committee for Biomerieux, AM Pharma and NxStage. JFT declares COl outside the submitted work: scientific board: Pfizer, Paratek, Nabriva, Merck; research grants to my university: Pfizer, Merck, Biomerieux; lectures fees: Merck, Pfizer, Biomerieux, Gilead. JR: consultancies/advisory boards: MSD (2019), QPEX (2019), Discuva Ltd (2019), Accelerate Diagnostics (2017), Bayer (2017), Biomerieux (2016); speaking fees: MSD (2018), Biomerieux (2018); industry grants: MSD (2017), The Medicines Company (2017), Cardeas Pharma (2016), Biomerieux (2019). JRZ: research grants: Pfizer, Merck; scientific board participation: Merck, BioMerieux, Eumedica, Pfizer; lecture fees: Merck, Pfizer, Correvio, Gilead. JDW: grant from the Flanders Research Foundation during the conduct of the study (Senior Clinical Investigator Grant); consulted for Accelerate, Bayer Healthcare, Cubist, Grifols, MSD, Pfizer (honoraria were paid to his institution).

\section{Open Access}

This article is licensed under a Creative Commons Attribution-NonCommercial 4.0 International License, which permits any non-commercial use, sharing, adaptation, distribution and reproduction in any medium or format, as long as you give appropriate credit to the original author(s) and the source, provide a link to the Creative Commons licence, and indicate if changes were made. The images or other third party material in this article are included in the article's Creative Commons licence, unless indicated otherwise in a credit line to the material. If material is not included in the article's Creative Commons licence and your intended use is not permitted by statutory regulation or exceeds the permitted use, you will need to obtain permission directly from the copyright holder. To view a copy of this licence, visit http://creativecommons.org/licen ses/by-nc/4.0/.

\section{Publisher's Note}

Springer Nature remains neutral with regard to jurisdictional claims in published maps and institutional affiliations.

Received: 24 September 2019 Accepted: 11 May 2020

Published online: 9 June 2020

\section{References}

1. Kollef MH (2001) Optimizing antibiotic therapy in the intensive care unit setting. Crit Care 5:189-195

2. Kollef MH (2001) Hospital-acquired pneumonia and de-escalation of antimicrobial treatment. Crit Care Med 29:1473-1475. https://doi. org/10.1097/00003246-200107000-00029

3. Antonelli M, Mercurio G, Nunno SD et al (2001) De-escalation antimicrobial chemotherapy in critically ill patients: pros and cons. J Chemother 13:218-223. https://doi.org/10.1179/joc.2001.13.Supplement-2.218

4. Tabah A, Cotta MO, Garnacho-Montero J et al (2016) A systematic review of the definitions, determinants, and clinical outcomes of antimicrobial de-escalation in the intensive care unit. Clin Infect Dis 62:1009-1017. https://doi.org/10.1093/cid/civ1199 
5. Garnacho-Montero J, Escoresca-Ortega A, Fernández-Delgado E (2015) Antibiotic de-escalation in the ICU: how is it best done? Current Opinion in Infectious Diseases 28:193-198. https://doi.org/10.1097/QCO.00000 00000000141

6. Silva BN, Andriolo RB, Atallah ÁN, Salomão R (2013) De-escalation of antimicrobial treatment for adults with sepsis, severe sepsis or septic shock. Cochrane Database Syst Rev (3):CD007934. https://doi. org/10.1002/14651858.CD007934.pub3

7. Tabah A, Bassetti M, Kollef MH et al (2019) Antimicrobial de-escalation in critically ill patients: a position statement from a task force of the European Society of Intensive Care Medicine (ESICM) and European Society of Clinical Microbiology and Infectious Diseases (ESCMID) Critically III Patients Study Group (ESGCIP). Intensive Care Med 46(2):245-265. https:// doi.org/10.1007/s00134-019-05866-w

8. Barlam TF, Cosgrove SE, Abbo LM et al (2016) Implementing an Antibiotic Stewardship Program: Guidelines by the Infectious Diseases Society of America and the Society for Healthcare Epidemiology of America. Clin Infect Dis 62:e51-e77. https://doi.org/10.1093/cid/ciw118

9. Rhodes A, Evans LE, Alhazzani W et al (2017) Surviving Sepsis Campaign: International Guidelines for Management of Sepsis and Septic Shock: 2016. Intensive Care Med 43:304-377. https://doi.org/10.1007/s00134-017-4683-6

10. Ruiz J, Ramirez P, Gordon M et al (2018) Antimicrobial stewardship programme in critical care medicine: a prospective interventional study. Med Intensiva 42:266-273. https://doi.org/10.1016/j.medin.2017.07.002

11. Vincent JL, Bihari DJ, Suter PM et al (1995) The prevalence of nosocomial infection in intensive care units in Europe. Results of the European Prevalence of Infection in Intensive Care (EPIC) Study EPIC International Advisory Committee. JAMA 274:639-644

12. Vincent J-L (2009) International study of the prevalence and outcomes of infection in intensive care units. JAMA 302:2323. https://doi.org/10.1001/ jama.2009.1754

13. Guo Y, Gao W, Yang $\mathrm{H}$ et al (2016) De-escalation of empiric antibiotics in patients with severe sepsis or septic shock: A meta-analysis. Heart Lung 45:454-459. https://doi.org/10.1016/j.hrtlng.2016.06.001

14. Paul M, Dickstein Y, Raz-Pasteur A (2016) Antibiotic de-escalation for bloodstream infections and pneumonia: systematic review and metaanalysis. Clin Microbiol Infect 22:960-967. https://doi.org/10.1016/j. cmi.2016.05.023

15. For the AZUREA Network Investigators, Leone M, Bechis C, et al (2014) De-escalation versus continuation of empirical antimicrobial treatment in severe sepsis: a multicenter non-blinded randomized noninferiority trial. Intensive Care Med 40:1399-1408. https://doi.org/10.1007/s0013 4-014-3411-8

16. van Heijl I, Schweitzer VA, Boel CHE et al (2019) Confounding by indication of the safety of de-escalation in community-acquired pneumonia: a simulation study embedded in a prospective cohort. PLoS ONE 14:e0218062. https://doi.org/10.1371/journal.pone.0218062

17. Electronic Data Capture (EDC), eCRF, ePRO, eCOA for clinical research | Castor. In: Castor EDC. https://www.castoredc.com/. Accessed 21 Sept 2019

18. Magiorakos A-P, Srinivasan A, Carey RB et al (2012) Multidrug-resistant, extensively drug-resistant and pandrug-resistant bacteria: an international expert proposal for interim standard definitions for acquired resistance. Clin Microbiol Infect 18:268-281. https://doi.org/10.111 1/j.1469-0691.2011.03570.x

19. Hernán MA (2018) How to estimate the effect of treatment duration on survival outcomes using observational data. BMJ 360:k182. https://doi. org/10.1136/bmj.k182

20. Hernán MA, Robins JM (2016) Using big data to emulate a target trial when a randomized trial is not available: table 1. Am J Epidemiol 183:758-764. https://doi.org/10.1093/aje/kwv254

21. Haukoos JS, Lewis RJ (2015) The propensity score. JAMA 314:1637. https ://doi.org/10.1001/jama.2015.13480

22. Hernan MA (2006) Estimating causal effects from epidemiological data. J Epidemiol Community Health 60:578-586. https://doi.org/10.1136/ jech.2004.029496

23. Hernan MA (2004) A definition of causal effect for epidemiological research. J Epidemiol Community Health 58:265-271. https://doi. org/10.1136/jech.2002.006361
24. Dalkey N, Helmer O (1963) An Experimental Application of the DELPHI Method to the Use of Experts. Manage Sci 9:458-467. https://doi. org/10.1287/mnsc.9.3.458

25. Okoli C, Pawlowski SD (2004) The Delphi method as a research tool: an example, design considerations and applications. Inf Manag 42:15-29. https://doi.org/10.1016/j.im.2003.11.002

26. (2019) R: The R project for statistical computing. https://www.r-proje ct.org/. Accessed 21 Sept 2019

27. Højsgaard S, Halekoh U, Yan J (2006) The R package geepack for generalized estimating equations. J Stat Softw 15(2):1-11

28. van der Wal Willem M, Geskus Ronald B (2011) ipw: An R Package for Inverse Probability Weighting. J Stat Softw 43(13):1-23

29. Hothorn T, Bretz F, Westfall P (2008) Simultaneous inference in general parametric models. Biometrical J 50(3):346-363

30. R Core Team (2019). R: a language and environment for statistical computing. R Foundation for Statistical Computing, Vienna. https://www.Rproject.org/

31. von Elm E, Altman DG, Egger $\mathrm{M}$ et al (2008) The strengthening the reporting of observational studies in epidemiology (STROBE) statement: guidelines for reporting observational studies. J Clin Epidemiol 61:344-349. https://doi.org/10.1016/j.jclinepi.2007.11.008

32. Tacconelli E, Cataldo MA, Paul M et al (2016) STROBE-AMS: recommendations to optimise reporting of epidemiological studies on antimicrobial resistance and informing improvement in antimicrobial stewardship. BMJ Open 6:e010134. https://doi.org/10.1136/bmjopen-2015-010134

33. Weiss E, Zahar J-R, Lesprit $P$ et al (2015) Elaboration of a consensual definition of de-escalation allowing a ranking of $\beta$-lactams. Clin Microbiol Infect 21:649.e1-649.e10. https://doi.org/10.1016/j.cmi.2015.03.013

34. De Bus L, Denys W, Catteeuw J et al (2016) Impact of de-escalation of beta-lactam antibiotics on the emergence of antibiotic resistance in ICU patients: a retrospective observational study. Intensive Care Med 42:1029-1039. https://doi.org/10.1007/s00134-016-4301-z

35. Heenen S, Jacobs F, Vincent J-L (2012) Antibiotic strategies in severe nosocomial sepsis: why do we not de-escalate more often?. Crit Care Med 40:1404-1409. https://doi.org/10.1097/CCM.0b013e3182416ecf

36. Eachempati SR, Hydo LJ, Shou J, Barie PS (2009) Does de-escalation of antibiotic therapy for ventilator-associated pneumonia affect the likelihood of recurrent pneumonia or mortality in critically ill surgical patients? J Trauma Injury Infection Critical Care 66:1343-1348. https://doi. org/10.1097/TA.0b013e31819dca4e

37. Knaak E, Cavalieri SJ, Elsasser GN et al (2013) Does antibiotic de-escalation for nosocomial pneumonia impact intensive care unit length of stay? Infect Dis Clin Pract 21:172-176. https://doi.org/10.1097/IPC.0b013e3182 79 ee87

38. Joffe AR, Muscedere J, Marshall JC et al (2008) The safety of targeted antibiotic therapy for ventilator-associated pneumonia: a multicenter observational study. J Crit Care 23:82-90. https://doi.org/10.1016/j. jcrc.2007.12.006

39. Giantsou E, Liratzopoulos N, Efraimidou E et al (2007) De-escalation therapy rates are significantly higher by bronchoalveolar lavage than by tracheal aspirate. Intensive Care Med 33:1533-1540. https://doi. org/10.1007/s00134-007-0619-x

40. Paskovaty A Pastores SM, Gedrimaite Z et al (2015) Antimicrobial deescalation in septic cancer patients: is it safe to back down? Intensive Care Med 41:2022-2023. https://doi.org/10.1007/s00134-015-4016-6

41. On behalf of the OUTCOMEREA Study Group, Weiss E, Zahar JR, et al (2016) De-escalation of pivotal beta-lactam in ventilator-associated pneumonia does not impact outcome and marginally affects MDR acquisition. Intensive Care Med 42:2098-2100. https://doi.org/10.1007/s0013 4-016-4448-7

42. De Waele JJ, Ravyts M, Depuydt P et al (2010) De-escalation after empirical meropenem treatment in the intensive care unit: Fiction or reality? J Crit Care 25:641-646. https://doi.org/10.1016/j.jcrc.2009.11.007

43. Morel J, Casoetto J, Jospé R et al (2010) De-escalation as part of a global strategy of empiric antibiotherapy management. A retrospective study in a medico-surgical intensive care unit. Crit Care 14:R225. https://doi. org/10.1186/cc9373

44. Gonzalez L, Cravoisy A, Barraud D et al (2013) Factors influencing the implementation of antibiotic de-escalation and impact of this strategy in critically ill patients. Crit Care 17:R140. https://doi.org/10.1186/cc12819 
45. Garnacho-Montero J, Gutiérrez-Pizarraya A, Escoresca-Ortega A et al (2014) De-escalation of empirical therapy is associated with lower mortality in patients with severe sepsis and septic shock. Intensive Care Med 40:32-40. https://doi.org/10.1007/s00134-013-3077-7

46. Madaras-Kelly K, Jones M, Remington R et al (2014) Development of an antibiotic spectrum score based on veterans affairs culture and susceptibility data for the purpose of measuring antibiotic de-escalation: a modified Delphi approach. Infect Control Hosp Epidemiol 35:1103-

1113. https://doi.org/10.1086/677633 